\title{
Health and social precursors of unemployment in young men in Great Britain
}

\author{
Scott M Montgomery, Mel J Bartley, Derek G Cook, Michael EJ Wadsworth
}

\begin{abstract}
Objective - To identify health and socioeconomic factors in childhood that are precursors of unemployment in early adult life and to examine the hypothesis that young men who become unemployed are more likely to have accumulated risks to health during childhood.
\end{abstract}

Design - Longitudinal birth cohort study. The amount of unemployment experienced in early adult life up to age 32 years was the outcome measure used. Exposure measures to indicate vulnerability to future ill health were: height at age 7 years and the Bristol social adjustment guide (BSAG) at age 11 years, a measure of behavioural maladjustment. Socioeconomic measures were: social class at birth, crowding at age 7 , qualifications attained before labour market entry, and region of residence.

Setting - Great Britain.

Subjects - Altogether 2256 men with complete data from the national child development study (NCDS). The NCDS has collected data on all men and women born in one week in 1958 and has followed them up using interviews, self completion questionnaires, and medical examinations at birth and at ages $7,11,16,23$ and 33 years. Results - A total of 269 men (11.9\%) experienced more than one year of unemployment between ages 22 and 32 years. Poor socioeconomic conditions in childhood and a lack of qualifications were associated with an increased risk of unemployment. Geographical region was also significant in determining the risk of unemployment. Men with short stature and poor social adjustment in childhood were more likely to experience unemployment in adult life, even after controlling for socioeconomic background, education, and parental height. These differences remained when those with chronic childhood illnesses were excluded from the analysis. The adjusted relative odds for experiencing more than one year of unemployment between ages 22 and 32 years for men who were in the top fifth of the BSAG distribution (most maladjusted) compared with those in the bottom fifth were $2.36(95 \%$ CI $1.49,3.73)$. The adjusted relative odds for experiencing more than one year of unemployment between ages 22 and 32 years for men who were in the bottom fifth of the distribution of height at age 7 years (indicating slowest growth) compared with those in the top fifth, were 2.41 (95\% CI 1.43, 4.04). Adult height was not significantly associated with unemployment.

Conclusion-The relationship between unemployment and poor health arises, in part, because men who become unemployed are more likely to have accumulated risks to health during childhood, reflected by slower growth and a greater tendency to behavioural maladjustment. Short stature in childhood is a significant indicator of poor socioeconomic circumstances in childhood and reflects earlier poor development.

(F Epidemiol Community Health 1996;50:415-422)

A higher prevalence of ill health ${ }^{1-4}$ and excess mortality ${ }^{5-7}$ has been associated with unemployment in many studies, and several processes to explain this have been proposed. One such process, known as 'direct health selection', asserts that poorer health itself increases the risk of unemployment, ${ }^{8-11}$ as unemployed men tend to be in poorer health before losing their job than those who do not become unemployed. Ill health has been clearly shown to be a risk factor for both initial job loss and for subsequent chances of re-employment. A second explanation for the link between unemployment and poor health, which can be described as 'causation', is that the experience of unemployment may be damaging to health. This has been explained in terms of job loss being a stressful life event ${ }^{13-17}$ and unemployment being a time of relative material hardship $^{18}$ and social exclusion. ${ }^{19}$ It has also been suggested that the experience of unemployment may lead to deterioration in health related behaviours. ${ }^{20}$

The 'causation' hypothesis is unlikely to be a complete explanation of the relationship between unemployment and poor health. Physical health does not necessarily decline significantly during a spell of unemployment; a number of studies failed to find an increase in morbidity among those who were continuously unemployed for up to 18 months. ${ }^{21}$ Indeed, some studies found that health may actually improve during a period of unemployment. ${ }^{22}$ However, Banks and Jackson ${ }^{17}$ and others ${ }^{14-16}$ have shown that psychological wellbeing can be diminished by the experience of unemployment. The chronic anxiety produced by unemployment may eventually affect physical health, ${ }^{23}$ but the underlying mechanisms which might explain this are poorly understood. 
The 'direct health selection' mechanism has been suggested as an explanation for the relationship between unemployment and excess mortality. ${ }^{24}$ If life threatening diseases were more prevalent in the unemployed than the employed, longitudinal data would show high mortality in the unemployed in the early periods of follow up, with a sharp decline in the mortality rate with increasing length of follow up. Research using linked census based data from England and Wales (the OPCS longitudinal study) and from the Nordic countries ${ }^{25} 26$ have not identified this pattern of mortality, making it unlikely that direct selection into unemployment of those with life threatening disease can account for the relationship between unemployment and excess mortality. ${ }^{56}$

Neither 'direct selection' nor 'causation' has been able to explain fully the relationship between unemployment and ill health. However, it is known that unemployment is a greater risk for those young people who have previously experienced less favourable family circumstances and educational attainment. ${ }^{27}$ This raises the possibility that there may be social and individual characteristics which put individuals at higher risk of both unemployment and ill health. Such a process has been termed 'indirect selection': those at greatest risk of unemployment may also be more vulnerable to excess mortality and morbidity because of social and personal characteristics independently of their experience of unemployment. ${ }^{28}$ This issue was examined using the British regional heart study, by considering the role of health related behaviours in explaining the relationship between unemployment and poor health. ${ }^{20}$

The social and personal characteristics that are associated with labour market performance and the risk of experiencing unemployment, have been described as 'social capital'. This term refers to the accumulation of material, educational, psychological, and cultural assets throughout life. It has been shown that material, educational, psychological, and cultural circumstances during childhood are related to many aspects of adult life opportunity, ${ }^{29} 3031$ including occupational attainment. ${ }^{32}$

Recently, a similar concept of 'health potential', has been described in studies that relate physical development in early life and the acquisition of health related habits in childhood and adolescence with health in later life. ${ }^{33}$ As the social capital argument describes the protective aspects of non-manual family background and experience of further or higher education against the risk of losing employment, so the protective aspects of optimal physical development have been found to relate to good health in middle life. ${ }^{33}$ Whereas social capital has been described in terms of education and financial assets, health potential may usefully be operationalised using height in childhood, a partially inherited trait that is also sensitive to socioeconomic circumstances ${ }^{29} 35$ and to other aspects of early life. ${ }^{37}$ Poor growth during early childhood has been shown to be associated with increased risks to adult health ${ }^{33}$ and shorter stature in adolescence has been associated with future experience of unemployment. ${ }^{38}$

The development of psychological health potential during childhood has been similarly demonstrated, ${ }^{39} 40$ and has been shown to be a source of risk and protection in terms of adult life adversity. ${ }^{41}{ }^{42}$ Since psychological aspects of the experience of unemployment seem likely to be associated with health, these too must be taken into account in a study of health and unemployment.

Most of the studies cited have investigated the relationship of unemployment with health in middle life, and while many have reviewed the pre-existing social and educational capital of their subjects, few have been concerned with the comparable question of health potential. This paper uses data on unemployment and health from a longitudinal birth cohort study to examine the relationship between social capital and physical and psychological health potential and unemployment in young men. Since the study has the advantage of data collected at birth and during childhood and adolescence, it is possible to explore prospectively the risk and preventive facility of 'social capital' and 'health potential' for unemployment between the ages of 22 and 33 years.

\section{Methods}

BACKGROUND AND SAMPLE

The data presented here are taken from the 1958 birth cohort study: the national child development study (NCDS), ${ }^{43}$ which is an ongoing national longitudinal study of all those living in Great Britain who were born between 3 and 9 March 1958. The study originated in the perinatal mortality survey (PMS, which collected data about the births of 17414 infants to parents resident in Great Britain. This represented $98 \%$ of births. ${ }^{45} 46$ There have been five subsequent data collection sweeps at ages $7,11,16,23$, and the most recent (NCDS5) was conducted in 1991 at age 33. The target sample for NCDS5 was 16455 , and this included all cohort members who had taken part in any of the previous surveys. A total of $86 \%$ of the target sample were traced for NCDS5. Altogether 11407 cohort members were interviewed in $1991,69 \%$ of the target population. It has been shown that despite sample attrition, the cohort has remained largely representative, although the most disadvantaged groups may be underrepresented. ${ }^{27} 44$

This paper is limited to men only, as unemployment in women was poorly estimated by the self completion questionnaire used to collect employment history data at NCDS5. When women were not employed they were far more likely to report home or child care than they were unemployment, even though it is likely that many would have taken work if it had been available. A total of 5588 men were interviewed at NCDS5, but as cases with any missing data were excluded, only 2256 men were used for these analyses. Those cases with missing data were slightly more likely to have experienced poorer socioeconomic conditions 
and they were slightly more likely to have experienced over one year of unemployment $(\mathrm{p}>0.02, \mathrm{n}=4999)$. However, the univariate relationships of height with unemployment and BSAG score with unemployment were very similar when cases with any missing values were included or excluded.

\section{MEASURES}

\section{Unemployment history}

A full employment history was collected at ages 23 and 33 years. Information on unemployment before age 22 years was not used because a high proportion of cohort members were in full time education up to that age, and therefore not at risk of unemployment. Unemployment data for 1991, when the cohort was 33 years of age, were not used in this analysis as interviews were conducted throughout 1991. The unemployment outcome variable comprised the total number of months of unemployment between ages 22 and 32 years, grouped into those with up to 12 months of unemployment (including those who had not been unemployed) and those with over 12 months of unemployment. This coding for unemployment was chosen as the recession of the early 1980 s resulted in a great deal of heterogeneity among those who experienced any unemployment, therefore we felt that it would be more appropriate to identify 'long term' unemployment. All men in the analysis were at risk of being or becoming unemployed during the study period; those men not at risk of being, or becoming, unemployed for at least seven years were excluded. Unemployment periods of fewer than three consecutive months were not included as they were poorly remembered.

\section{Childhood sociodemographic circumstances}

Parental social class and crowding in the home were used as indicators of social and economic conditions during childhood. The RegistrarGeneral's social class based on the father's occupation when the cohort member was born was used, and where the father was not present, the mother's own social class was used. Social classes I and II were combined for analysis. Crowding was used as an indicator of social disadvantage ${ }^{47}$ to provide a more accurate measure of standard of living. ${ }^{48}$ This was based on the number of persons per room, excluding kitchens and bathrooms, when the cohort members were age 7 years. This was divided into three categories: up to one person per room; more than one to one and a half persons per room; and more than one and a half persons per room. The last category represents the most disadvantaged group.

\section{Region}

Place of residence at age 7 years was used to represent region. Great Britain was divided into 11 standard regions. Region at age 7 years was used as this pre-dates labour market entry and any mobility that was a consequence of labour market adversity or success.
Qualifications

Qualifications gained through education or training before age 23 years were grouped into six ordinal categories indicating highest qualification achieved as follow: no qualifications, low level qualifications, ' $O$ ' level or equivalent qualifications, ' $A$ ' level or equivalent qualifications, other higher qualifications below university level, university degree and equivalents.

\section{Health potential}

Height at age 7 years was measured by a school doctor. The height range at age 7 was $1.016 \mathrm{~m}$ to $1.473 \mathrm{~m}$. Parents' self reported heights were recorded during an interview in 1969. Cases where the heights of both natural parents were not available were excluded from the analysis. The self reported adult height of cohort members was recorded during the interview at age 23 years. Chronic illness and disability up to age 16 was assessed by medical examination, medical records, and parental reports. The physicians' reports included a measure of severity for all conditions reported in the summary of health at age 16 .

Childhood psychological health was assessed using the Bristol social adjustment guide (BSAG), which was designed to describe the child's behaviour in particular settings. ${ }^{49}$ Teachers completed the BSAG for study members at age 11 to assess the child's behaviour and attitudes. The BSAG may be divided into 'syndrome' scores to give a quantitative assessment of behaviour. The summed syndrome scores used for this analysis, indicate the total amount of behavioural deviance or maladjustment in terms of being unforthcoming, withdrawal, depression, anxiety for acceptance by adults, hostility towards adults, 'writing off' of adults and adult standards, anxiety for acceptance by children, hostility towards children, restlessness, 'inconsequential' behaviour, miscellaneous symptoms and miscellaneous nervous symptoms. The BSAG score thus has a range from 0 to 56 symptoms

\section{STATISTICAL METHODS}

The relation of unemployment with measures of health potential (height at age 7 years and psychological status at age 11 years) and social capital (social class at birth, home crowding at age 7 years, and highest educational qualification attained) was examined by cross tabulation and logistic regression, in which height and BSAG score were included as linear terms. For descriptive purposes, height and BSAG score were recoded into groups which were as close to fifths of the distributions as possible. In the case of height, it was not possible to recode into exact fifths due to rounding to the nearest inch prior to conversion to centimetres. Further analysis controlling for potential confounders was carried out using multiple logistic regression.

All analyses were conducted using SPSS in a UNIX environment. ${ }^{50}$ For the logistic regression, all categorical variables were entered into the logistic model as binary dummies. Cases with values missing for any variable were excluded from all analyses. 
Table 1 Experience of unemployment for over one year between ages 22 and 32 years (\% and relative odds). The relative odds are adjusted for all other variables. Height and BSAG score were entered as continuous variables and the relative odds are those for a $1 \mathrm{~cm}$ or 1 point increase respectively ( $n=2256)$

\begin{tabular}{|c|c|c|c|c|c|c|c|c|}
\hline \multirow[b]{2}{*}{ Variable } & \multirow[b]{2}{*}{ No } & \multirow[b]{2}{*}{$(\%)$} & \multicolumn{3}{|l|}{ Unadjusted } & \multicolumn{3}{|l|}{ Adjusted } \\
\hline & & & Relative odds & $(95 \% C I)$ & $p$ value & Relative odds & $(95 \% C I)$ & $p$ value \\
\hline Class at birth: & & & & & 0.0000 & & & 0.0002 \\
\hline I/II & 441 & $(6.6)$ & 1.00 & & & 1.00 & & \\
\hline IIInm & 258 & $(10.1)$ & 1.59 & $(0.92,2.77)$ & & 1.38 & $(0.78,2.43)$ & \\
\hline IIIm & 1149 & (11.0) & 1.75 & $(1.15,2.66)$ & & 1.21 & $(0.77,1.89)$ & \\
\hline IV & 256 & $(18.8)$ & 3.28 & $(2.01,5.35)$ & & 2.08 & $(1.23,3.53)$ & \\
\hline V & 152 & (26.3) & 5.07 & $(3.01,8.55)$ & & 2.78 & $(1.58,4.92)$ & \\
\hline Crowding: & & & & & 0.0000 & & & 0.2224 \\
\hline Up to 1 persons/room & 1382 & $(9.0)$ & 1.00 & & & 1.00 & & \\
\hline$>1-1.5$ persons/room & 508 & (14.6) & 1.73 & $(1.27,2.35)$ & & 1.21 & $(0.87,1.69)$ & \\
\hline$>1.5$ persons/room & 366 & (19.4) & 2.44 & $(1.78,3.36)$ & & 1.38 & $(0.95,2.01)$ & \\
\hline Qualifications: & & & & & 0.0000 & & & 0.0229 \\
\hline None & 227 & (26.4) & 3.16 & $(2.13,4.68)$ & & 1.89 & $(1.23,2.92)$ & \\
\hline Less than $O$ level & 253 & $(16.6)$ & 1.75 & $(1.15,2.67)$ & & 1.49 & $(0.96,2.33)$ & \\
\hline O level & 617 & $(10.2)$ & 1.00 & & & 1.00 & & \\
\hline A level & 698 & (10.3) & 1.01 & $(0.71,1.45)$ & & 1.10 & $(0.76,1.60)$ & \\
\hline Further & 221 & $(6.8)$ & 0.64 & $(0.36,1.15)$ & & 0.74 & $(0.41,1.36)$ & \\
\hline Degree & 240 & $(7.1)$ & 0.67 & $(0.38,1.17)$ & & 0.98 & $(0.56,1.77)$ & \\
\hline Region: & & & & & 0.0000 & & & 0.0010 \\
\hline N Western & 218 & $(17.9)$ & 3.41 & $(1.93,6.02)$ & & 2.53 & $(1.40,4.58)$ & \\
\hline Scotland & 278 & $(17.6)$ & 3.35 & $(1.94,5.78)$ & & 2.33 & $(1.31,4.15)$ & \\
\hline Northern & 199 & (17.6) & 3.34 & $(1.87,5.97)$ & & 2.44 & $(1.34,4.45)$ & \\
\hline Wales & 126 & $(15.1)$ & 2.78 & $(1.43,5.40)$ & & 2.13 & $(1.07,4.23)$ & \\
\hline Midlands & 215 & (14.4) & 2.64 & $(1.46,4.76)$ & & 2.09 & $(1.14,3.85)$ & \\
\hline $\mathrm{E}$ and $\mathrm{W}$ Riding & 198 & $(13.1)$ & 2.36 & $(1.28,4.36)$ & & 1.98 & $(1.05,3.72)$ & \\
\hline N Midlands & 169 & $(9.5)$ & 1.64 & $(0.82,3.25)$ & & 1.38 & $(0.68,2.80)$ & \\
\hline S Western & 171 & (8.2) & 1.39 & $(0.69,2.84)$ & & 1.16 & $(0.56,2.39)$ & \\
\hline London and SE & 333 & $(6.0)$ & 1.00 & & & 1.00 & & \\
\hline Eastern & 190 & $(5.8)$ & 0.96 & $(0.45,2.05)$ & & 0.81 & $(0.37,1.75)$ & \\
\hline Southern & 159 & $(5.7)$ & 0.94 & $(0.42,2.11)$ & & 0.81 & $(0.35,1.85)$ & \\
\hline Height age $7(\mathrm{~cm})$ & 2256 & (11.9) & 0.93 & $(0.91,0.96)$ & 0.0000 & 0.95 & $(0.92,0.97)$ & 0.0001 \\
\hline BSAG score & 2256 & (11.9) & 1.04 & $(1.03,1.05)$ & 0.0000 & 1.03 & $(1.01,1.04)$ & 0.0005 \\
\hline Paternal height (cm) & 2256 & (11.9) & 0.98 & $(0.96,1.00)$ & 0.0236 & 1.00 & $(0.99,1.03)$ & 0.3384 \\
\hline Maternal height $(\mathrm{cm})$ & 2256 & (11.9) & 0.98 & $(0.96,1.00)$ & 0.1299 & 1.02 & $(0.99,1.04)$ & 0.1649 \\
\hline
\end{tabular}

\section{Results}

Altogether 269 men (11.9\%) experienced more than one year of unemployment between ages 22 and 32 years. Both social class at birth and crowding at age 7 years reflect material and cultural circumstances in childhood and they were powerfully predictive of unemployment (see table 1). Altogether $26.3 \%$ of those born into social class $\mathrm{V}$ had had over a year of unemployment, while only $6.6 \%$ of those in class I and II had experienced a similar amount of unemployment. Nine per cent of those in the least crowded households experienced over one year of unemployment compared with $19.4 \%$ in the most crowded.

Having no qualifications was found to be a significant risk factor for subsequent unemployment; $26.4 \%$ of those without qualifications had experienced more than a year of accumulated unemployment. Those who were at the lowest risk of unemployment had remained in full time 'further education' but had not gone on to 'higher education'. Altogether $6.8 \%$ of the 'further education' group had experienced over a year of unemployment. A similar proportion $(7.1 \%)$ of those who had obtained a university or polytechnic degree were subject to this accumulation of unemployment. The protective value of higher education may have been diminished in this cohort by the economic recession of the early $1980 \mathrm{~s}$, which made it more difficult for graduates to obtain employment when they first entered the labour market.

Significant variation in unemployment risk by geographical region was observed; $17.9 \%$ of those in the north western region had experi- enced over one year of unemployment but at the opposite extreme, only $5.7 \%$ of those living in the southern region had been unemployed for over a year. This reflects geographic variation in the economy.

Height at age 7 years was inversely associated with experience of unemployment. $20.2 \%$ of those who were in the lowest height group at age 7 subsequently experienced over one year of unemployment between 1980 and 1990 , compared to $8.0 \%$ of those in the tallest group (table 2).

The BSAG score at age 11 years was also highly predictive of subsequent unemployment. Some $6.7 \%$ of the least deviant group, compared with $19 \%$ of the most deviant, had reported over one year of unemployment (table 2). The relationship is not entirely linear, as the bottom fifth of the BSAG distribution is clearly distinct, with the gradient through the higher relative odds somewhat shallower.

CONTROLLING FOR CONFOUNDING VARIABLES The effect of controlling for confounding variables can be seen in table 1 , where height and BSAG were fitted as linear terms in a multiple logistic regression model, in which the dependent variable was coded as 0 or 1 representing experience of more than 12 months of unemployment. The effect of adjustment can be seen by comparing the unadjusted coefficients for height and BSAG with the adjusted coefficients. These coefficients were moved towards one by adjustment, but both remained highly statistically significant. Table 2 provides a more descriptive analysis in which height and BSAG were modelled as group variables corresponding to fifths of their distributions. 
Table 2 Experience of unemployment for over one year between ages 22 and 32 years. Height at age 7 years and BSAG score at age 11 years are presented as group ordinal variables. The relative odds are adjusted for class at birth, crowding, qualifications, region, height, BSAG score, and parental height $(n=2256)$

\begin{tabular}{|c|c|c|c|c|c|c|c|c|}
\hline \multirow[b]{2}{*}{ Variable } & \multirow[b]{2}{*}{ No } & \multirow[b]{2}{*}{$(\%)$} & \multicolumn{3}{|l|}{ Unadjusted } & \multicolumn{3}{|l|}{ Adjusted } \\
\hline & & & Relative odds & $(95 \% C I)$ & p value & Relative odds & $(95 \% C I)$ & $p$ value \\
\hline Height at age $7 \mathrm{y}$ : & & & & & 0.0000 & & & 0.0012 \\
\hline 1 shortest & 392 & (20.2) & 2.90 & $(1.84,4.56)$ & & 2.41 & $(1.43,4.04)$ & \\
\hline 2 & 293 & $(15.0)$ & 2.03 & $(1.23,3.33)$ & & 1.81 & $(1.05,3.12)$ & \\
\hline 3 & 444 & $(10.2)$ & 1.30 & $(0.80,2.12)$ & & 1.23 & $(0.73,2.06)$ & \\
\hline 4 & 766 & $(9.4)$ & 1.19 & $(0.76,1.87)$ & & 1.20 & $(0.75,1.92)$ & \\
\hline 5 tallest & 362 & $(8.0)$ & 1.00 & & & 1.00 & & \\
\hline BSAG score: & & & & & 0.0000 & & & 0.0049 \\
\hline 1 least maladjustment & 509 & $(6.7)$ & 1.00 & & & 1.00 & & \\
\hline 2 & 393 & (9.4) & 1.45 & $(0.89,2.36)$ & & 1.43 & $(0.87,2.36)$ & \\
\hline 3 & 549 & (11.7) & 1.84 & $(1.19,2.85)$ & & 1.78 & $(1.13,2.79)$ & \\
\hline 4 & 379 & (14.0) & 2.27 & $(1.44,3.57)$ & & 1.96 & $(1.22,3.15)$ & \\
\hline 5 most maladjustment & 426 & $(19.0)$ & 3.28 & $(2.15,5.01)$ & & 2.36 & $(1.49,3.73)$ & \\
\hline
\end{tabular}

Controlling for the social capital variables, region, BSAG score and, parental height resulted in the estimated relative odds for height increasing slightly to 0.95 (95\% CI $0.92,0.97$ ) from 0.93 (95\% CI $0.91,0.96)$. The adjusted relative odds for experiencing over one year of unemployment between ages 22 and 32 years for men who were in the bottom fifth of the distribution of height at age 7 years (indicating slowest growth), when compared to those in the top fifth, were 2.41 (95\% CI 1.43, 4.04). Figure 1 shows the relative odds of experiencing over one year of unemployment between ages 22 and 23 years by mean value for each of the height groups (table 2). Parental height was not significantly associated with risk of unemployment.

The relative odds for BSAG score were slightly reduced from 1.04 (95\% CI 1.03 , $1.05)$ to 1.03 (95\% CI $1.01,1.04)$ by controlling for the social capital variables, region and height at age 7 . The adjusted relative odds for experiencing over one year of unemployment between ages 22 and 32 years for men who were in the top fifth of the BSAG distribution (most maladjusted) compared with those in the bottom fifth, were 2.36 (95\% CI 1.49, 3.73). Figure 2 plots for each BSAG group (table 2) the relative odds of experiencing over one year of unemployment between ages 22

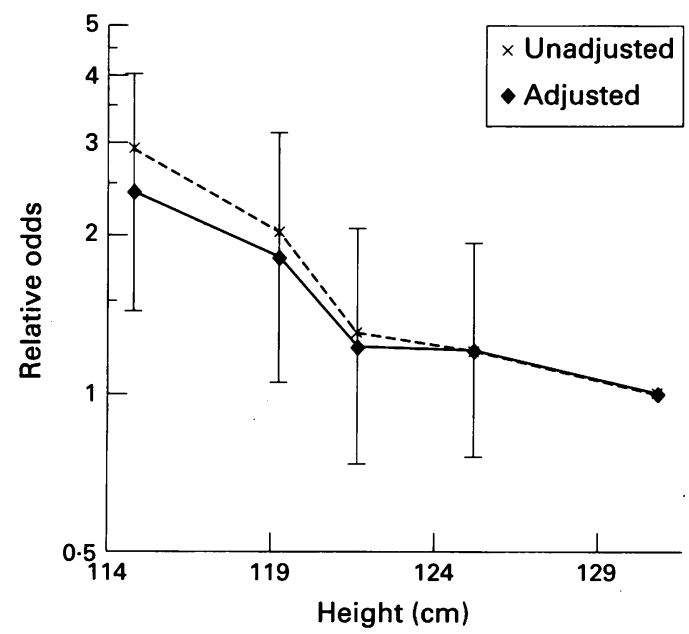

Figure 1 Relative odds ( $95 \%$ CI) of experiencing more than one year of unemployment between ages 22 and 32 in relation to height groups at age 7 years, adjusted for social class at birth, crowding, qualifications, region, Bristol social adjustment guide score, and parental height. and 23 years in relation to the mean value for each BSAG score group.

Multiple logistic regression for risk of unemployment was also performed where cohort members who had a moderate to severe chronic illness or disability at age 16 (85 cases) were excluded. The regression coefficients for height at age 7 and BSAG score at age 11 were almost identical in the models including and excluding the cases who had suffered moderate to severe chronic illness or disability at age 16 .

Table 3 shows the relationships of height at age 7 with unemployment and height at age 23 with unemployment, both adjusted and unadjusted for confounding variables. Adult height (at age 23) was weakly predictive in the unadjusted model, with a $p$ value of 0.0103 , but in the adjusted model the $\mathrm{p}$ value was increased to 0.4293 . In the adjusted model which also included adult height, height at age 7 had relative odds for unemployment of 0.94 and a $\mathrm{p}$ value of 0.0010 . Height at age 7 was thus a significantly better predictor of risk of unemployment than adult height.

\section{Discussion}

Unemployment in early adulthood was related to social capital, defined in terms of childhood socioeconomic conditions and education, and to childhood health potential, measured as

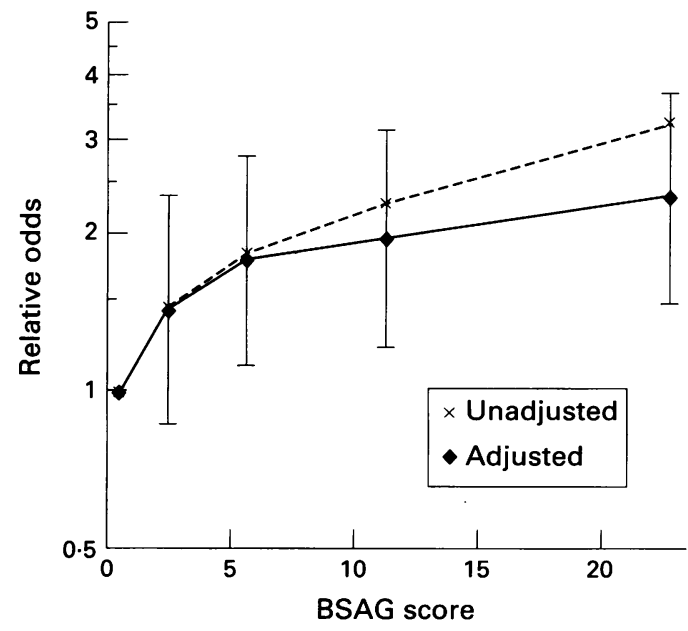

Figure 2 Relative odds (95\% CI) of experiencing more than one year of unemployment between the ages of 22 and 32 in relation to the Bristol social adjustment guide score groups at age 11 years, adjusted for social class at birth, crowding, qualifications, region, and height. 
Table 3 The relative odds of experiencing over one year of unemployment between age 22 and 32 years in relation to height at ages 7 and 23 years. Adjusted for social class at birth, crowding, qualifications, region of residence, BSAG score and parental height $(n=2075)$

\begin{tabular}{|c|c|c|c|c|c|c|}
\hline \multirow[b]{2}{*}{ Variable } & \multicolumn{3}{|l|}{ Unadjusted } & \multicolumn{3}{|l|}{ Adjusted } \\
\hline & Relative odds & $(95 \% C I)$ & p value & Relative odds & $(95 \% C I)$ & $p$ value \\
\hline Height at age $7 \mathrm{y}(\mathrm{cm})$ : & 0.94 & $(0.92,0.96)$ & 0.0000 & 0.94 & $(0.91,0.98)$ & 0.0010 \\
\hline Height at age $23 \mathrm{y}(\mathrm{cm})$ & 0.97 & $(0.96,0.99)$ & 0.0103 & 1.01 & $(0.98,1.04)$ & 0.4293 \\
\hline
\end{tabular}

height at age 7 and social adjustment at age 11 . The relationship between health potential in children and later labour market disadvantage was only slightly diminished by controlling for measures of social capital and geographical region. The association between lower levels of social capital and labour market disadvantage is well established; material and cultural deprivation experienced in childhood often result in reduced opportunities throughout life, ${ }^{3031}$ working through processes such as poor educational performance. ${ }^{31}$ The considerable effect of regional variation in the economy and therefore local demand for labour is shown by the strength of association between area of residence and unemployment, even when controlling for measures of social capital and health potential.

The high relative risk of unemployment associated with shorter stature at age 7 years and lower levels of psychological health at age 11 years is largely independent of measures of social capital. However, this relationship does not appear to be due to selection into unemployment because of pre-existing illness or disability. When cohort members with clinically diagnosed chronic illnesses and disabilities were excluded from the analysis the relationship of unemployment to height at age 7 years and social adjustment at age 11 years remained.

Those of shorter stature at age 7 years were not at greater risk of unemployment as adults because of their height. If employers were selecting for height, this would be on the basis of adult height, which was not significantly related to unemployment. Delayed growth during childhood is more important as a predictor of unemployment than adult height; children of shorter stature are not necessarily of short stature as adults due to later growth spurts. ${ }^{51}$ The weak relationship between adult height at age 23 years and unemployment was unlikely to be due to measurement error, as measured height at age 33 years also showed a similar weak relationship with unemployment.

The relationship between height at age 7 years and unemployment may be because short stature at age 7 years, or more accurately slow growth to age 7 years, adds another dimension to the measurement of childhood socioeconomic and psychosocial adversity. The importance of the influence of early life environmental factors for both childhood height and later socioeconomic outcomes is further supported by experiments using twins reared apart and together. ${ }^{52}$ Stature has been shown to be associated with family circumstances in childhood ${ }^{53}$ and growth may add extra sensitivity to the other, conventional measurements of socioeconomic background and qualifications. The conditions leading to slow growth may also have implications for cognitive development, as well as other forms of psychological development and thereby for labour market performance and coping strategies in later life. Growth is an additional indicator of disadvantage and may also be a highly sensitive marker for achievement. Slow growing children were likely to attain lower level educational qualifications when compared with their peers from the same social class. We would also expect slow growth to be associated with lower grades within levels of qualifications. We suspect that, regardless of the level of labour market entry, the slow growers would have greater difficulty in finding or keeping employment in the labour market of the 1980 s, which included periods of significant economic recession. Further detailed analysis of employment history would be required to investigate the precise mechanisms that account for greater labour market disadvantage among men who grew slowly as children.

Other mechanisms leading to short stature at age 7 years are likely to include poor nutrition and other factors such as disrupted sleep patterns. Growth hormone is released during sleep and its secretion rate falls if sleep is disrupted. ${ }^{37}$ The secretion of other hormones required for normal physical development is also stimulated by growth hormone. ${ }^{36}$ Conditions during childhood that result in short stature could also produce reduced levels of social capital, not accurately measured by conventional indicators such as social class and crowding, resulting in future labour market disadvantage. Adverse conditions during childhood are also likely to influence psychological health, ${ }^{54}$ as reflected by social adjustment at age 11 years. As with height, lower levels of psychological health may be a sensitive measure of poor childhood conditions and stressful life events. The argument for direct selection into unemployment due to poor psychological health is plausible, as employers might be less likely to employ or continue to employ those with a greater tendency to behavioural maladjustment.

The measures of physical and psychological health potential indicate vulnerability to future illness. This can be demonstrated for psychological health potential by research showing that childhood behaviour and personality are associated with adult psychiatric disorder or tendency to psychiatric disorder. ${ }^{56}$ This is further supported by work linking childhood behaviour and temperament with adult 
neurosis. ${ }^{57-61}$ Similarly, height has been shown to be an indicator for the risk of future morbidity, as can be demonstrated by the association of short stature with a higher mortality from stroke, ischaemic heart disease, rheumatic heart disease and chronic bronchitis. ${ }^{62}$ However, the associations between childhood health potential and later excess mortality and morbidity should not be thought of as a direct link. A study of Finnish men aged 42-60 years, ${ }^{63}$ found that adult socioeconomic conditions were far more important in determining risk of all cause cardiovascular mortality than childhood conditions. This highlights the importance of conditions throughout life for their contribution to risk of excess morbidity. Those children in the Finnish study who grew up in disadvantaged conditions would have been more likely to become disadvantaged adults. Lower levels of health potential resulting from childhood circumstances may be carried forward into further socioeconomic disadvantage in adulthood, including labour market disadvantage, resulting in an accumulation of risk to health.

The concept of indirect health selection does not undermine the argument that the experience of unemployment, or the process of becoming unemployed, can damage physical and psychological health. The experience of unemployment may result in biological and psychological insults, but those who experience unemployment are more likely to have lower levels of health potential as they have experienced other insults in earlier life. This is consistent with recent work on accumulation of disadvantage throughout life, which has shown that individuals with measures of low health potential and disadvantage in earlier life are more likely to experience disadvantage throughout their lives. ${ }^{64}$ This accumulation of disadvantage further erodes health potential and may eventually result in excess mortality and morbidity. A spell of unemployment can also result in diminished human capital by rendering individuals less likely to obtain stable employment after being unemployed. ${ }^{65}$ Platt $^{66}$ suggests that unemployment may exacerbate underlying psychiatric conditions, which in some cases results in suicide or parasuicide. In a similar way, the physical and psychological characteristics of men, which result from lower levels of health potential, may render them more vulnerable to illness precipitated or exacerbated by unemployment. Those with lower levels of psychological wellbeing in childhood may be more vulnerable to mental illness, particularly if subjected to any additional precipitating factor such as unemployment. Further psychological deterioration can be observed in young people who experience continuing unemployment. ${ }^{67}$ Chronic stress and the possibly lower ability to deal with it might also, eventually, result in physical illness. ${ }^{23}$. Unemployment may well play an important mediating role between disadvantage in early life and morbidity and mortality in later life and this requires further investigation using longitudinal data tracking individuals from early life, through education, early employment and on into middle age and later life.
This paper forms part of a project funded by the British Economic and Social Research Council grant no R000234697.

1 Cook DG, Cummins RO, Bartley MJ, Shaper AG. Health of unemployed middle aged men in Great Britain. Lancet 1982;i: 1290-4.

2 Daniel WW, Stilgoe E. Where are they now? A follow up study of the unemployed. London: Political and Economic Planning, 1979

3 Moylan S, Davies R. The disadvantages of the unemployed. Employment Gazette 1980; 88: 830-2.

4 Moylan S, Millar J, Davies R. For richer, for poorer - DHSS cohort study of unemployed men. London: HMSO, 1984.

5 Moser KA, Fox AJ, Jones DR. Unemployment and mortality in the OPCS longitudinal study. Lancet 1984;ii 1324-8.

6 Moser KA, Goldblatt PO, Fox AJ, Jones DR. Unemployment and mrtality: comparison of the 1971 and 1981 longitudinal study samples. $B M 7$ 1987;294: 86-90

7 Morris JK, Cook DG, Shaper AG. Loss of employment and mortality. BMF 1994;308: 1135-9.

8 Cook DG. A critical view of the unemployment and health debate. The Statistician 1985;34:73-82.

9 Wagstaff A. Unemployment and health: some pitfalls for the unwary. Health Trends 1986;18: 79-81.

10 Wadsworth MEJ. In: Wilkinson RG ed. Class and health Cambridge: Tavistock, 1986: 50-74

11 Robinson N, Yateman NA, Protopapa LE, Bush L Unemployment and diabetes. Diabetic Med 1989;6: 797-80.

12 Clausen B, Bjomdal A, Hjort PF. Health and reemployment in a two year follow-up of long term unemployed. F Epidemiol Community Health 1993;47: unemp.

13 Jahoda $M$. The impact of unemployment in the 1930 s and the 1970s. Bulletin of the British Psychological Society 1979 32: 309-14.

14 Warr PB. Job loss, unemployment and psychological well-being. In: Allen V, Van de Vliert E eds. Role transitions. New York: Plenum Press, 1984.

15 Warr PB. Work, unemployment and mental health. Oxford: Oxford University Press, 1987.

16 Isakson K. Unemployment and mental health and the psychological function of work in male welfare clients in Stokholm. Scand f Soc Med 1989;17: 165-9.

17 Banks MH, Jackson PR. Unemployment and the risk of minor psychiatric disorder in young people: crossminor psychiatric disorder in young people: cross-
sectional and longitudinal evidence. Psychol Med. 1982;12: 189-98.

18 White M. Against unemployment. London: Policy Studies Institute, 1991 .

19 Whelan CT. The role of income, life-style deprivation and financial strain in mediating the impact of unemployment on psychological distress - evidence from the Republic of Ireland. Fournal of Occupational and Organizational Psychology 1992;65: 331-4.

20 Morris JK, Cook DG, Shaper AG. Non-employment and changes in smoking, drinking and body weight. $B M Y$ 1992:304: 536-41.

21 Bartley MJ. Unemployment and health: selection or causation? Sociology of Health and Illness 1987;10: 41-67.

22 Ramsden S, Smee C. The health of unemployed men: DHSS cohort study. Employment Gazette 1981;89: 3 97-40 1

23 Kaplan HB. Social psychology of the immune system: A conceptual framework and review of the literature. Soc Sci Med 1991;33: 909-23.

24 Stern J. The relationship between unemployment, morbidity and mortality in Britain. Population Studies 1983; 37(1): 61-74.

25 Martikainen P. Unemployment and mortality among Finnish men. $B M \mathcal{F}$ 1990;301: 407-11

26 Iversen L, Andersen 0, Andersen PK, Christoffersen K, Keiding N. Unemploment and mortality in Denmark. BMF 1987;295: 879-84.

27 Power C. Manor 0, Fox AJ. Health and class. The early years. London:Chapman and Hall,1991.

28 Valkonen T, Martikainen P. The association between unemployment and mortality: Causation or selection? In Proceedings of IUSSP Seminar Premature adult mortality in developed countries. Taormina, Italy 1-5 June 1992.

29 Douglas JWB, Ross JM, Simpson HR. All our future. London: Peter Davies, 1968.

30 Pilling D. Escape from disadvantage. London: The Falmer Press, 1990.

31 Wadsworth MEJ. The imprint of time. Childhood history and adult life, Oxford: Clarendon Press, 1991.

32 Elias P, Blanchfiower D. The occupations, earnings and work histories of young adults - who gets the good jobs? Department of Employment research paper no 68. London: Department of Employment, 1987.

33 Barker DJP. Mothers, babies and disease in later life. London: British Medical Journal Publications, 1994.

34 Dahl E,Kjaersgaard P. Social mobility and inequality in mortality. Eur f Public Health 1993; 3: 124-32.

35 Tanner JM. Growth at adolescence. Oxford: Blackell, 1955. 
36 Preece MA, Holder AT. The somatomedins: A family of serum growth factors. In: O'Riordan JLH ed. Recen advances in endocrinology and metabolism. Vol 2. Edinburgh advances in endocrinology and

37 Preece M A. Prepubertal and pubertal endocrinology. In: Falkner J, Tanner JM. Human growth. 2nd ed. London Plenum Press, 1985

38 West $P$ Future imperfect: Teenagers and Health. MRC News 1994;63: 36-40.

39 Harrington R, Bredenkamp D, Groothues C, Rutter M Fudge $\mathrm{H}$, Pickles A. Adult outcomes of childhood and adolecent depression - links with suicidal behaviours. $f$ Child Psychol Psychiatry 1994;35: 1309-19.

40 Zoccolillo M, Pickles A, Quinton D, Rutter M. The outcome of childhood conduct disorder - implications for defining adult personality disorder and conduct cisorders. defining adult personality diso
Psychol Med 1992; 22: 971-86.

41 Cherry N. Persistent job changing - is it a problem? fournal of Occupational Psychology 1976;49: 203-21.

42 Block J, Gjerde PF. Depressive symptoms in late adolescence: A longitudinal perspective on personality anticedents. In: Rolf J, Masten AS, Cicchetti D, Nuechterlein $\mathrm{KE}$, Weintraub $\mathrm{S}$ eds. Risk and protective factors in the development of psychopathology. Cambridge: Cambridge University Press, 1989.

43 Shepherd P. The national child development study:An introduction to the background to the study and the methods of data collection. NCDS working paper no 1. London: Social Statistics Research Unit, City University, 1985.

44 Ferri E ed. Life at 33. London: National Children's Bureau, 1993.

45 Butler N R, Bonham D G. Perinatal mortality. Edinburgh: Churchill Livingstone, 1963

46 Butler NR, Albennan ED eds. Perinatal problems. Edinburgh: Churchill Livingstone, 1969.

47 Essen J, Fogelman K, Head J. Children's housing and their health and physical development. Child: Health, care and development. 1978;4: 357-69.

48 Goldblatt PO. Mortality and alternative social classifications. In: Goldblatt P ed. Longitudinal study: mortality and social organisation. London: HMSO, 1990: 163-92.

49 Stott DH. The social adjustment of children. London:University of London Press, 1969

50 Norusis M. J. SPSS user's guide. Chicago: SPSS Inc, 1990.

51 Greco L, Power C, Peckham C. Adult outcome of norma children who are short or underweight at age 7 years. $B M \mathcal{F}$ 1995; 310: 696-700.

52 Lichtenstein P, Harris JR, Pedersen NL, McCleam GE Socioeconomic status and physical health, how are they
related? An empirical study based on twins reared apart related? An empirical study based on twins reared apart
and twins reared together. Soc Sci Med 1992;36: 441-50.
53 Terrell TR, Mascie-Taylor CGN. Biosocial correlates of stature in a 16-year-old British cohort. $f$ Biosoc $S \mathrm{Ci}$ stature in a $16-y$.

54 Cohen P, Brook JS, Cohen J, Velez CN,Garcia M. Common and uncommon pathways to adolescent psychopathology and problem behaviour. In: Robins L, Rutter $M$ eds. Straight and devious pathway from childhood to adulthood. Cambridge: Cambridge University Press, 1988.

55 Dunn J. Normative life events as risk factors in childhood. In: Rutter M. Studies of psychosocial risk. Cambridge: Cambridge University Press, 1988.

56 Rodgers B. Behaviour and personality in childhood as predictors of adult psychiatric disorder. $f$ Child Psychol Psychiatry 1990; 31: $393-414$.

57 Warren W. A study of adolescent psychiatric in-patients and the outcome six or more years later-II. The follow-up study. $\mathcal{f}$ Child Psychol Psychiatry 1965; 6: 141-60.

58 Pritchard M, Graham P. An investigation of a group of patients who have attended both the child and adult departments of the same psychiatric hospital. Brf Psychiatry 1966; 112: 603-12.

59 Robins LN. Deviant children grown up. Baltimore: Williams and Wilkins, 1966.

60 Mellsop GW. Psychiatric patients seen as children and adults: childhood predictors of adult illness. $f$ Child Psychol adults: childhood predictors

61 Kandel DB, Davies M. Adult sequelae of adult depressive symptoms. Arch Gen Psychiatry 1986; 43: 255-62.

62 Barker D J P, Osmond C, Golding J. Height and mortality in the counties of England and Wales. Ann Hum Biol 1990; 17: 1-6.

63 Lynch JW, Kaplan GA, Cohen RD, Kauhanen J, Wilson TW, Smith NL, Salonen JT. Childhood and adult socioeconomic status as predictors of mortality in Finland. Lancet 1994; 343: 524-27.

64 Bartley MJ, Power C, Blane D, Davey Smith G, Shipley M. Birth weight and later socioeconomic disadvantage: evidence from the 1958 British cohort study. BMF 1994;309: 1475-9.

65 Gershuny J, Marsh C. Unemployment in work histories. In: Gallie D, Marsh C, Vogler C eds. Social change and the experience of unemployment. Oxford: Oxford University Press, 1994; 66-114.

66 Platt S. Unemployment and suicidal behaviour: A review of the literature. Soc Sci Med 1984; 2: 93-115.

67 Hammarstrom A, Janlert U, Theorell T. Youth unemployment and ill health: results from a 2-year follow-up study. Soc Sci Med 1988; 26: 1025-33. 